\title{
Democracias pluralistas: ¿una alternativa para el Gobierno colombiano?*
}

Fecha de entrega: 18 de noviembre de 2019

Fecha de evaluación: 30 de noviembre de 2019

Fecha de aprobación: 1 de diciembre de 2019

Angélica María Rodríguez Ortiz

\section{Resumen}

En las últimas décadas se evidencia la crisis que afronta el sistema de gobierno colombiano, a tal grado que parte del pueblo ha puesto en duda la efectividad de la democracia que se sustenta en el contrato social. Pese a ello, es preciso decir que la democracia - como lo han sostenido diversos filósofos a través de la historia- es la forma de gobierno más próxima al estado de la naturaleza humana, por operar bajo el principio de igualdad jurídica y social. Por tal razón, este artículo pretende mostrar cómo las democracias pluralistas pueden ser una alternativa de gobierno para operar en el pluralismo político que ha pululado en los últimos años en la sociedad colombiana y con ello alcanzar representatividad y participación democrática real, que dé solución a los problemas del contexto. Visto así, no se trata de eliminar

* Artículo producto de investigación en torno al proyecto de investigación sobre filosofía política en el que la doctora Angélica trabaja en los últimos meses.

Citar como: Rodríguez Ortiz, A. M. (2020). Democracias pluralistas: ¿una alternativa para el Gobierno colombiano? Cuadernos de Filosofía Latinoamericana, 41(122), 89-110.

DoI: https://doi.org/10.15332/25005375/5530

* Doctora en Filosofía por la Universidad Pontificia Bolivariana, magister en Educación y licenciada en Filosofía y Letras. Docente investigadora del grupo SEAD-UAM - Universidad Autónoma de Manizales. ORCID: http://orcid.org/0000-0002-7710-9915. Correo electrónico: angelica.rodriguez276@gmail. com; amrodriguez@autonoma.edu.co 
la democracia como forma de gobierno, sino de descentralizar el poder, en aras de plantear soluciones mayormente efectivas.

Palabras claves: democracias, pluralismo político, democracias pluralistas, ciudadanía diferenciada, formación ciudadana.

\section{Pluralist Democracies: An Alternative for the Colombian Government?}

\section{Abstract}

In recent decades, the crisis faced by the Colombian government has become evident, so much so that a portion of the people has questioned the effectiveness of democracy based on the social contract. In spite of this, it must be said that democracy - as many philosophers have argued - is the form of government most germane to the state of human nature, since it operates under the principle of legal and social equality. For this reason, this article aims to show how pluralistic democracies may be an alternative form of government to operate in the political pluralism that has swarmed in recent years in Colombian society, so as to achieve real democratic representativeness and participation which may solve the context's problems. Thus, this it is not a proposal to eliminate democracy as a form of government, but to decentralize power in order to propose mostly effective solutions.

Keywords: democracies, political pluralism, pluralistic democracies, differentiated citizenship, citizenship education. 


\section{Introducción}

Las prácticas ciudadanas de las últimas décadas evidencian la crisis que enfrenta la democracia representativa y participativa de un sistema de autoridad soberana que tiende a degenerar en plutocracia. Ante esto, aparecen alternativas como las democracias pluralistas que apuestan por ciudadanías diferenciadas, en aras de favorecer el poder político de la colectividad.

Las democracias pluralistas, requeridas para el funcionamiento de la ciudadanía diferenciada, promulgan igualdad jurídica real que evidencie el cumplimiento de los lineamientos formales que han sido estipulados en las declaraciones contractuales de los Estados de occidente; en aras de favorecer la justicia social, pensada desde las necesidades de los contextos particulares. Para alcanzar tal cometido, se requiere un cambio en la participación y en la formación ciudadana en pro del compromiso racional, intencional y consciente que debe adoptar cada actor en este modelo de ciudadanía, el cual rescata la diferencia y prolifera el pluralismo político. Un compromiso real con el contrato social, en aras de hacer valer el cumplimiento de este por parte de aquellos que son elegidos para representarnos.

Este escrito no pretende exponer que la democracia representativa y participativa deben eliminarse o buscar otro tipo de gobierno diferente, como lo sugieren varias encuestas realizadas en las últimas décadas, en las que se muestra que "los resultados para Colombia denotan la presencia de una franja importante de la población insatisfecha con la democracia 'realmente existente', y que apoyaría eventualmente una forma de gobierno distinta a ésta" (Duque, 2012, p. 22); tampoco aduce al hecho de que las democracias estén muriendo, como lo han expuesto Levitsky y Ziblatt (2018); por el contrario, invita a pensar en nuevos significados y usos que promuevan el concepto de democracia en la actualidad y, con esto, pensar en nuevas formas para el ejercicio de esta. En otras palabras, incita a salir de la concepción clásica que concibe una democracia absolutista, la cual delega el poder a los elegidos para representar al pueblo, y movernos hacia una democracia pluralista, en la cual se haga efectiva la representatividad del pueblo como fuerza de poder organizacional, dando un nuevo sentido a la ciudadanía. 


\section{Democracia y pluralismo político}

Los problemas sociales y políticos de nuestra época requieren hablar de nuevas formas de democracia y, a su vez, invita a una movilización semántica del concepto. Estas comprensiones conllevan a nuevos ejercicios democráticos para un contexto donde prima el pluralismo político y, con esto, iniciar nuevos procesos de formación ciudadana.

La crisis real de la democracia en los últimos años en Latinoamérica no radica en la forma de gobierno per se, como lo han supuesto algunos analistas para quienes la democracia es un tipo de gobierno que no brinda respuesta a las necesidades del contexto. El problema real radica en el abuso de poder por parte de los representantes elegidos por la ciudadanía. Contrariedad que, desde la Antigüedad, Platón había develado en sus estudios sobre el poder político. De igual forma, la crisis proviene de la queja constante de un pueblo que no asume de manera crítica y a conciencia su rol como ciudadano y, tanto en su participación como en su abstinencia, evidencia una carencia de memoria histórica y amplia ignorancia a la hora de elegir a sus representantes.

Una de las razones por las cuales la democracia centralizada y global no llega a ser efectiva es el abuso de poder, entendido como la facultad de ejercer la fuerza o el dominio evidenciado en la acción, a través del ejercicio de control y autoridad sujetos a intereses hedonistas. Esto se evidencia, entre otras cosas, en la fuerte manipulación del pueblo por parte de los gobernantes, que construyen discursos con falacias para convencer. Mismas con las que los representantes en el poder intentan "maquillar" sus acciones e introducen, a través de la retórica, miedos sin fundamento a un pueblo cuyos ciudadanos están incapacitados para identificarlas ${ }^{1}$.

La manipulación del pueblo a través del discurso se ha evidenciado en diferentes oportunidades, uno de los más recientes casos, en Colombia, fueron las pasadas elecciones presidenciales en el 2017; mismas en las que apareció el neologismo castrochavismo y con el cual se construyó un discurso plagado de falacias ad baculum - entre otras más- que movilizaron los temores de la ciudadanía. La participación ciudadana evidenció la ignorancia frente al tema a la hora de elegir al nuevo mandatario, y el

1 El problema no nace en la actualidad. Esta misma preocupación ha estado presente desde la democracia en la Antigua Grecia. Platón en su libro VII la República dejó en evidencia la importancia de la formación ciudadana para el ejercicio del poder en el ámbito público y el abuso cometido por los gobernantes en el ejercicio del poder. Cfr. Platón. República (1998). 
reconocimiento de su error participativo no se ha hecho esperar ${ }^{2}$. No obstante, este es solo uno de muchos ejemplos en que los gobernantes introducen discursos para movilizar las acciones de un pueblo carente de capacidades de lectura crítica y que sucumbe a las intenciones de quienes manipulan el poder a través del uso de la palabra. Los últimos Gobiernos son una clara muestra de lo aquí ilustrado.

Ante esta situación, en el último año se han movilizado diferentes alternativas políticas que buscan salir de la polaridad manifiesta entre los partidos políticos tradicionales de ultra derecha y extrema izquierda. No obstante, pese a la aparición de nuevas alternativas políticas, el ejercicio de poder democrático continúa centralizado y no da respuesta a los problemas específicos de este contexto. Razón por la cual urge revisar las nuevas demandas del pluralismo político a la luz de una nueva forma de gobernar que descentralice el poder ${ }^{3}$, un gobierno que desde la democracia otorgue poder real al pueblo y estipule unas normativas que solucionen los problemas de un territorio y tejido social determinado.

A lo anterior, se suman nuevos problemas como la vulneración de los derechos de grupos diferenciados que se reconocen como "minorías" y el acallamiento de líderes de la oposición y de todo aquel que cuestione a quienes se han tomado el poder, como se evidencia en la realidad colombiana de los últimos años. Se requieren, entonces, cambios efectivos que den respuesta a las particularidades de los contextos y a sus diferencias. Ante esto, se sugiere pensar la democracia desde una concepción pluralista que apueste por una ciudadanía diferenciada, en la que se descentralice el poder; una forma de gobierno en el que los grupos plurales planteen políticas propias para su autogobierno, como se empieza a presentar en algunos países de Latinoamérica. Uruguay, México y Argentina, por ejemplo, proponen un giro hacia las democracias plurales y ciudadanías diferenciadas, en aras de descentralizar el poder y que este sea

2 Bastaron pocos dias en el ejercicio del nuevo mandatario para que con sus acciones, contrarias a sus discursos, generara dudas razonables en parte del pueblo que lo eligió para atacar sus ideas y forma de representar a la colectividad. El bombardeo de protestas en medios de comunicación, redes sociales y en las calles es apenas un indicio ante las desidias de este gobierno. A esto se suma en el 2019, las movilizaciones de un paro de algo más de una semana en el cual la ciudadanía expuso su queja desde diferentes sectores y el Estado obstaculizó el derecho a la libre protesta, a través de la fuerza pública. Hecho que ocasionó la muerte de jóvenes que alzaban su voz en contra de las políticas del actual gobierno.

3 Lanzaro (2004) plantea que "el pluralismo, como elemento distintivo de los diferentes tipos de democracia, es un tópico central de la teoría y de la ciencia política" (p. 103). El pluralismo ha estado presente en el significado que convoca el concepto "democracia" como forma de gobierno. 
mayormente efectivo. No obstante, de estos tres países podría decirse que Uruguay es el primero que ha pasado del discurso a la acción. "Las democracias de tipo pluralista se caracterizan, por trazos de separación, distribución y participación en lo que toca al poder político y a la estructura institucional, los modos de gobierno y los ejercicios de autoridad pública” (Lanzaro, 2004, p. 103). Según lo muestra Lanzaro en sus estudios, Uruguay es un claro ejemplo de este tipo de gobierno. En otras palabras, las democracias pluralistas se convierten en una alternativa para escapar de los carruseles políticos en los que cada gobernante designa los cargos de acuerdo con los intereses de su partido político.

La transición de una democracia centralista a una pluralista ha empezado a tener acogida en Latinoamérica, en aras de escapar del despotismo de los gobernantes que asumen el poder como un régimen autoritario y articulan a su maquinaria todo un gabinete legislativo de "conocidos" para desempeñar los cargos públicos. Lo vivido por América Latina es un atentado a la democracia. Un gobernante, perpetrado en el poder, moviendo los hilos detrás de la representatividad de otro es igual al gobernante que cambia la constitución para que el pueblo acepte la reelección. Ambos hechos están en contra del ideal perseguido por los primeros contratos sociales que aparecieron a finales del siglo xIx.

Las primeras constituciones latinoamericanas comprendieron la necesidad de asegurar, en especial en cuanto al Poder Ejecutivo, la alternancia de sus titulares en el Gobierno. Por eso, en la mayoría de los casos, se proscribió la reelección inmediata. Pero esta prohibición contradecía los imperativos de la realidad social y de la fuerza política y fáctica de los que detentaban el poder, luego de haber llegado a él como consecuencia de una revolución, de un golpe de Estado, de un motín o de una elección, cuyos resultados, en este último caso, eran muchas veces fruto de la coacción, la prepotencia, la intimidación o el fraude. (Gros, 2002, p. 152)

Pocos países latinoamericanos han respetado el pacto. Quizá el mejor ejemplo del respeto por este tipo de políticas gubernamentales ha sido Uruguay como lo muestran Castellanos y Pérez (1981) y Lanzaro (2004). Un país que ha intentado escapar de las prácticas de corte populista de dudosa calidad en cuestiones democráticas. Podría decirse que en la actualidad México también da muestra de esto en sus elecciones del 2018. En la práctica del nuevo gobernante y su equipo de trabajo se evidencia un 
ejercicio de democracia pluralista, aun cuando no se ha postulado un fundamento de tal tipo como sí lo ha hecho abiertamente Uruguay. Por otra parte, Chile, Brasil y Ecuador han redireccionado sus pasos en busca de la descentralización del poder $\mathrm{y}$, aunque no lo han logrado, la ciudadanía se ha volcado en el último año a las calles en su busqueda.

Latinoamérica siente el abuso del poder en su gobierno democrático y, en especial, Colombia lo padece intensamente en las últimas décadas; razón por la cual, quizá las democracias pluralistas sean esa "nueva forma de gobierno" que espera la sociedad colombiana. Un nuevo ejercicio democrático plural en el que el pueblo se empodere de la ciudadanía, sin necesidad de rechazar o eliminar la posibilidad de un gobierno democrático, pues, como lo promulgó Spinoza, el Estado democrático tiene, entre otras bondades, que operar bajo el principio de la igualdad - jurídica-; además que

[...] con preferencia a todos los demás, es el Estado más natural y el que se aproxima más a la naturaleza de la libertad. En este Estado nadie transfiere a otro su derecho natural, sino que lo entrega a la mayor parte de la sociedad de la que él es parte. Por lo cual, en un Estado de democracia todos siguen siendo iguales como en el estado natural. (Spinoza, 1986, p. 341)

Algo que también refirió Rousseau (1991 y 2003) al buscar una forma de gobierno que equilibre los intereses del pueblo y de los gobernantes. Las democracias pluralistas son una alternativa para acabar con "el despotismo que representa la forma extrema de separación entre el interés de los gobernantes y de los gobernados, y la imposición del interés particular de los primeros sacrificando el de los segundos" (Vergara, 2012, p. 21), dado que permiten al pueblo empoderarse para el ejercicio del poder a través del contrato social y dar solución a las particularidades de su contexto, sin imponerse de forma despótica como se ha hecho en el poder centralizado.

\section{Democracias pluralistas y contrato social}

Alcanzar un estado de equilibrio entre la naturaleza humana, los intereses de la colectividad y lo que concierne al ejercicio del poder de quien nos representa no es tarea fácil; máxime si se considera que la naturaleza humana —como lo plantean Spinoza y Hobbes - es egoísta. Sin embargo, no es una labor imposible; tal vez por esto, el gobierno democrático, tal y como lo conciben Spinoza (1986) y 
Rousseau (2003), permite alcanzar en cierta medida dicha armonía, puesto que este se presenta enmarcado en un pacto social, en un contrato lingüístico que regula las acciones tanto del representante del pueblo, como del pueblo mismo. "En efecto, en el pacto social spinozista, la transferencia de derechos del individuo a la colectividad garantiza la igualdad del estado de naturaleza y preserva al máximo la libertad natura" (Villaverde, 2002, p. 2). El pacto social, además, se constituye en el mecanismo jurídico que garantiza el principio de igualdad sobre el cual opera el gobierno democrático. El contrato es, entonces, en cualquier tipo de democracia, un instrumento regulador, tanto de la participación como de la representatividad. Y, para el caso de las democracias pluralistas, es el elemento que permite al grupo garantizar el respeto de su dignidad e integridad.

El representante elegido por la colectividad está regulado bajo el pacto social a la hora de ejercer el poder político; asimismo, los ciudadanos deben estar capacitados para esto. No obstante, la realidad que se evidencia en nuestro país da cuenta de que tal cosa no ocurre. Gran parte de los ciudadanos ignoran que pueden usarlo para controlar la práctica de los gobernantes en el poder. El problema radica en el desconocimiento de lo pactado y en el bajo compromiso asumido con lo que ha sido declarado constitucionalmente por participantes del pacto. Resulta inconcebible que hayan pasado más de tres centenios, desde la creación del contractualismo en la Modernidad, y los ciudadanos no se reconozcan aún como actores sustanciales en la creación del pacto social; pese a que desde su consolidación en Latinoamérica, entre 1810 y 1830, “el 'constitucionalismo' fue considerado como una de las características individualizantes del proceso revolucionario que en toda América Latina garantizaba la organización política e institucional de los nuevos Estados independientes" (Gros, 2002, p. 147).

Ahora bien, a la luz de los acontecimientos podría decirse que la democracia absolutista acaba por ser limitada para las exigencias y cambios sociales en nuestra sociedad — como se ha expuesto - dado que, como lo sostiene Villaverde (2002), se otorga el poder y sometimiento de los ciudadanos al gobernante; pese a sus debilidades este es el modelo de gobierno que se ha impuesto y permanece en Occidente. Es precisamente, este tipo de gobierno, y sus debilidades, lo que ha llevado a declarar la democracia en crisis; puesto que, bajo esta concepción, el poder no reside en la colectividad, como se esperaría, sino en los intereses de quien ha sido elegido para ejecutarlo y que, a la larga, acaba por ignorar los ideales reales de la democracia representativa. 
La propuesta del Estado democrático sustentada por Spinoza, contrario a lo que afirma Villaverde (2002), se opone a esta concepción absolutista en la cual el sujeto se desprende por completo de su poder para darlo a la sociedad y someterse a los designios del gobernante. En su concepción, el filósofo de Ámsterdam propone un tipo de gobierno democrático en el que el pacto social pasa a ser un mecanismo del sujeto para controlar el ejercicio del poder en quien lo representa. Podría decirse que este es un tipo de gobierno que brinda las bases conceptuales a las propuestas de gobierno basadas en la democracia plural; puesto que en este tipo de democracia, más que dejar el poder a un representante, se exige un acompañamiento de este ejercicio por parte de los ciudadanos. Lo que Canto (2017) ha denominado como el modelo gerencial de la democracia, en el cual:

La participación ciudadana no es un fin en sí misma, sino un medio para mejorar la gestión pública; sus modalidades y alcances dependerán del fin buscado en cada caso. Aunque en principio este enfoque incluye todo el continuo (información, comunicación, consulta, debate y decisión) lo común es que no incluya la decisión. La participación llegará sólo hasta donde se requiera que llegue e incluirá sólo a aquéllos que contribuyan a alcanzar los fines buscados, normalmente grupos acotados de ciudadanos. (pp. 59-60)

Desde esta perspectiva, la formación ciudadana se convierte en una herramienta fundamental si se quiere lograr un compromiso real con un ejercicio prudente y racional de este tipo de gobierno y, también, una responsabilidad en la construcción y seguimiento del contrato para alcanzar una sociedad justa, tal y como lo exponen Spinoza (1986), Rousseau (2003) y Platón (1998).

Lo anterior se sustenta en que la democracia pluralista convoca un nuevo significado para comprender el concepto y, así, el tipo de gobierno; además, con esto se reclaman nuevas prácticas democráticas en las que se exige mayor compromiso en el ejercicio de la ciudadanía. Las cuales se alejan de la concepción clásica, pues, en este tipo de gobierno que atiende a las diferencias del contexto y de la población, el ciudadano crea y conoce las leyes que están estipuladas en el contrato que le rige. El individuo está en la capacidad de reconocerse a sí mismo como parte de una sociedad que contribuye en la creación del contrato, así como de vigilar y controlar el ejercicio de poder de aquellos que ha elegido para representarle en el gobierno, dado que en la organización social radica la fuerza y el poder. 
En términos de Canto (2017), la democracia como forma de gobierno en un Estado pluralista:

Subraya el empoderamiento de las ciudadanías en sentido amplio, no sólo de las organizaciones de base asociativa, sino de los ciudadanos de a pie, con procesos de cambio institucional que les otorgan el poder de tomar decisiones vinculantes en los asuntos públicos a través de mecanismos o dispositivos de democracia participativa y directa; por ejemplo, los presupuestos participativos o los referendos y plebiscitos, entre otros. En los modelos más avanzados de este enfoque, la participación democrática de la ciudadanía incorpora procesos deliberativos que permiten confrontar los intereses específicos para avanzar a decisiones aceptables para todos los participantes. (p. 57)

Así pues, en las democracias pluralistas, todo ciudadano debe ser consciente de su rol en la sociedad a la hora de participar e identificar sus deberes y derechos. Elegir a conciencia aquellos hombres prudentes que lo representan al hacer parte del grupo diferenciado al que pertenecen. Representantes ante quienes no se someterán; por lo cual, deben formarse para ejercer el poder. De igual forma, quien es elegido por la colectividad para representar, por disposición de la colectividad, deberá ser prudente para alcanzar los objetivos sociales. La prudencia, entonces, sobresale por ser una virtud esencial en el ejercicio democrático; mismo que se alcanza en el perfeccionamiento de la razón. "En general, todas las cosas que podemos desear honradamente se refieren a estas tres fundamentales: conocer las cosas por sus causas primeras; domar nuestras pasiones o adquirir la costumbre de la virtud; vivir en seguridad y con buena salud" (Spinoza, 1986, p. 34). La prudencia termina por ser la virtud que debe predominar en el ejercicio de las fuerzas de poder y en un mundo plural debe ir acompañada de la tolerancia, puesto que son las que permiten al pueblo y a sus representantes no desviarse de los ideales perseguidos y aceptar que su ejercicio se da en un mundo en el que prima la diversidad. Un equilibrio necesario para mediar entre las diferentes concepciones que persigue el pluralismo político.

La prudencia y la tolerancia se requieren dado que las democracias pluralistas son:

Polivalentes porque, de un lado, tienden a satisfacer distintas concepciones de los principios que deben presidir el ejercicio del Poder, y porque, prácticamente, su significación depende de la coyuntura, de manera especial de la naturaleza 
de los problemas debatidos y de las tendencias de las fuerzas políticas que dominen en aquel momento el país. (Bordeau, 1982, p. 27)

En otras palabras, la democracia pluralista no es una cuestión que dependa de las voluntades de los gobernantes, sino de fuerzas colectivas; es decir, que para Bordeau (1982), este tipo de gobierno no aduce a una democracia de individuos, sino de poderes legitimados que tienen como responsabilidad la rectitud política en medio de la coexistencia de múltiples poderes proporcionados por las fuerzas sociales, organizados de forma espontánea. Lo que exige prudencia y tolerancia en el ejercicio del poder.

Ahora bien, es preciso anotar que la concepción de democracia pluralista, aquí presentada, hace referencia a un significado similar al concepto de democracia en la Modernidad, brindado por Spinoza al proponerlo como el gobierno más natural al estado humano, pues convoca a que la sociedad ejerza la fuerza, a través de un representante, en defensa de la igualdad jurídica y la libertad y partiendo del reconocimiento de sus diferencias y necesidades. Si bien Spinoza no habló de una democracia pluralista, es preciso decir que su concepción de democracia también postula que la colectividad tiene, a través del pacto social, el control de una recta política por parte de quienes la representan, lo que implica, al igual que en el pluralismo democrático, el ejercicio de una ciudadanía crítica.

El pluralismo, que responde la fórmula de poder abierto, les exige a los individuos mucho más que abnegación: un renunciamiento total, porque como la sociedad es tal como el Poder la hace no existe refugio para ellos en ningún otro lugar. (Bordeau, 1982, p. 30)

En este sentido, tanto la concepción de democracia planteada por Spinoza como la de una democracia pluralista exigen procesos en los cuales los ciudadanos se comprometan con el contrato social que han conformado; así como la adopción de una capacidad crítica para ejercer el compromiso adquirido al elegir a los representantes y exigirles el cumplimiento de las acciones esperadas. En otras palabras, exige una participación real, que favorezca la coherencia entre lo que se postula en el pacto y lo que se realiza en la práctica. De igual forma, en ambos tipos de democracia se demandan valores como la prudencia y la tolerancia por parte de quienes eligen y quienes representan las fuerzas del poder del pueblo y una capacidad para concentrar en una sola fuerza social el poder de los individuos. 
Podría decirse que, en cierta medida, las características esenciales de las democracias pluralistas fueron esbozadas tempranamente por Spinoza, cuando planteó que

\begin{abstract}
[...] el medio más seguro que aconsejan la razón y la experiencia es formar una sociedad fundada sobre leyes y establecerse en una región determinada y concentrar las fuerzas individuales en un solo cuerpo, el cuerpo social. $¡ Y$ hace falta no poca habilidad y vigilancia para formar y mantener una sociedad! Por esto sería más segura y más duradera y menos expuesta a los golpes de la fortuna, la sociedad fundada y dirigida por hombres prudentes. (Spinoza, 1986, p. 9)
\end{abstract}

Así, la concepción de Spinoza escapa a una postura clásica y absolutista de la democracia, como se le ha atribuido (Villaverde, 2002), puesto que es la sociedad la que concentra sus fuerzas para elegir a los hombres que la representarán como cuerpo social, y se acerca más a una concepción pluralista, en la que los ciudadanos están activos y vigilantes en el cumplimiento de las obligaciones por parte del Estado. Lo anterior se sustenta, en que, tanto en la concepción de democracia expuesta por Spinoza como en la concepción pluralista - Bordeau (1982), Favela (2007), Lanzaro (2000 y 2004) y otros más - "se dibuja así una franja de representaciones colectivas de clase, que acceden por esta vía a un estatus de autoridad pública y participan directamente en los procesos decisorios" (Lanzaro, 2004, p.124).

\title{
Democracias pluralistas y ciudadanía diferenciada
}

En la lucha por el cambio, los movimientos políticos que promulgan nuevos discursos legales que irrumpen con las propuestas tradicionales plantean la importancia de repensar el rol ciudadano y el compromiso adquirido dentro de este. Asimismo, el sistema educativo ha generado nuevos espacios donde pensar de manera consciente cómo formar ciudadanos críticos, seres con pensamiento social que se reconozcan como actores capaces de transformar la realidad. Quizás el pueblo esté despertando del letargo en el que ha estado por tantos años y esto ha hecho que los actores sociales se piensen en su contexto, reconozcan sus problemas y expongan su voz. La situación de Colombia en el 2019 , con un paro de varias semanas y con una asistencia multitudinaria a las marchas convocadas, refleja la insatisfacción de la ciudadanía. No es una cuestión de partidos políticos, sino de dignidad, de respeto por su integridad. Exigir el cumplimiento de la obligación asumida por el Estado, en aras de que sus derechos fundamentales sean respetados, es apenas el inicio que convoca el cambio social. 
Los ciudadanos han asumido una postura más crítica. Cuestionan su entorno, las leyes y las nuevas formas de gobierno, así como a los gobernantes que incumplen en representar al pueblo. Reclaman garantías y ponen en tela de juicio la validez de una democracia representativa que en realidad no los representa. En términos de Bello (2014): "En la disputa por la ciudadanía emergen actores y grupos sociales que resisten y demandan derechos, pero también hacen cuestionamientos para dotar la ciudadanía del componente cultural y evitar la tendencia homogeneizadora de la igualdad ciudadana” (p. 132). Así, los problemas específicos del contexto, la diversidad, la organización social y la necesidad de pensar en unas políticas propias hacen que el pueblo reclame una ciudadanía diferenciada.

Las minorías reclaman por su integridad y la protección del Estado y este hace oídos sordos a su clamor. El pueblo reclama, entre muchas cosas, la muerte de los líderes sociales de las comunidades indígenas, la indolencia del Estado ante masacres cometidas en contra de niños inocentes y el distanciamiento del gobierno de un proceso de paz que apenas iniciaba. Exige, lo que Leyva (2005) ha denominado una gramática moral. El reconocimiento de sus particularidades y la defensa de sus tradiciones, pues el contrato social resulta ser excluyente y no garantiza la dignidad humana.

La marginación, la discriminación social, étnica, cultural y económica es una muestra de que es hora de hacer una revisión a los lineamientos legales de nuestro país. Como bien lo expone Bello (2014), las minorías reclaman al sentirse víctimas de la exclusión y degradación humana. Esta crisis las lleva a exigir respeto y reafirmarse como actores sociales,

[...] por lo que es importante impulsar el reconocimiento para garantizar la dignidad e integridad del individuo y facilitar la autorrealización del ser humano en interacción con sus compañeros de grupo y el reconocimiento de la sociedad; a fin de eliminar todo aquello que le menosprecia y devalúa. (Bello, 2014, p. 133)

Esta idea social y moral expresada por Bello y Leyva es una apuesta por construir una sociedad justa mediante el reconocimiento de la dignidad humana; así, en la diversidad los derechos y deberes - que han sido universalizados - adquieren un poder específico y transformador. En este sentido, reconocer la diferencia de estos grupos minoritarios y de las comunidades ancladas a un territorio específico lleva 
a valorar, en gran medida, la autonomía y la libertad, tanto del individuo como de su territorio, sin desconocer que este hace parte de un Estado y de una organización social.

Ante esta situación, es preciso reconocer que en Colombia la brecha crece a pasos agigantados. El Estado y sus representantes políticos imponen sus políticas y las quejas del pueblo agobiado no pasan de ser luchas simbólicas. Nuestro caso es similar al de México, puesto que como lo muestra Bello (2014), "no existe un régimen de autonomía amplia (político-territorial) legalmente reconocido, los procesos atómicos de facto, practicados por gran números de comunidades indígenas, al persistir como formas de autogobierno comunitario se convierten en "luchas simbólicas de resistencia cotidiana” (Bello, 2014, p. 135). Se exige el reconocimiento, la obligación por parte del Estado de velar por su integridad, pero no se transforma la política y, con esto, todo continúa igual.

No obstante, vemos que entender la ciudadanía, como lo propone Brett (2009) y como está planteada en la Constitución Política de Colombia de 1991, no es suficiente para lo que está afrontando el país. Es decir, la ciudadanía como "el reconocimiento por parte del Estado de la igualdad de todos sus miembros como portadores de derechos y deberes” (Brett, 2009, p. 12) no llegó a ser útil y cada vez es menos efectivo. Si bien existen derechos universales, que deben ser garantizados por los gobernantes para todos los ciudadanos - en esto la teoría es clara-, la realidad nos muestra que el ejercicio de la democracia representativa de orden centralista no da cuenta de esto. Los derechos colectivos no son tal cosa, ni garantizan la participación de los actores sociales que componen el Estado; no existen condiciones de igualdad para todos los ciudadanos y no se da respuesta a las particularidades del contexto. Las políticas centralistas no tienen el alcance esperado para proteger a los grupos sociales minoritarios. Así pues, un Estado plural e incluyente - como lo plantea Bello- debe reconocer e implementar marcos normativos plurales en los derechos colectivos favorezcan la individualidad. Puesto que el ciudadano es un sujeto que participa y construye con el colectivo.

La ciudadanía diferenciada permite, entonces, pensar en prácticas de gobiernos locales y políticas propias. Desde esta perspectiva, los individuos asumen su compromiso social con la colectividad en cuestiones políticas, económicas y culturales. Podría decirse que una ciudadanía diferenciada es una apuesta por construir una identidad política. Así, la democracia permanece, pero ya no como un ejercicio ajeno al pueblo, en el 
que eligen unos pocos que representan a la mayoría, sino con un pueblo empoderado que participa de manera activa en su representación. En otras palabras, una sociedad diversa exhorta una forma de democracia plural que favorezca la ciudadanía diferenciada y, a su vez, esta es la que constituye e instituye la democracia plural para crear sus propias políticas y dar solución a los problemas de su territorio. En este sentido, la democracia pluralista conlleva el empoderamiento social y político de los ciudadanos. En la identificación de las diferencias el ciudadano se reconoce como actor en un colectivo político y participa de los asuntos públicos, favorece la multiculturalidad y piensa en nuevas formas dar respuesta a los problemas del contexto.

El reconocimiento de un Estado multicultural, tal y como lo ha planteado Kymlicka (1996a y 1996b), conlleva pensar en un tipo de ciudadanía que trabaje en pos de los derechos diferenciados de los grupos y en la creación de políticas de autogobierno. Para Kymlicka:

[...] una teoría liberal de los derechos de las minorías debe explicar cómo los derechos de las minorías coexisten con los derechos humanos, y también cómo los derechos de las minorías están limitados por los principios de la libertad individual, democracia y justicia social. (1996a, 19)

De este modo, cuando se crean las políticas en defensa de los derechos de los colectivos plurales se favorece a la comunidad que lo requiere y no a la mayoría - como ocurre en la democracia centralista-. En términos de Tamayo (2006), una ciudadanía diferenciada debe tener en cuenta la adopción de tres tipos de derechos: poliétnicos, de representación y de autogobierno, además de velar moral y políticamente por sus intereses; por lo cual, se involucra el seguimiento y cumplimiento por parte de los representantes.

De igual forma, quién representa al grupo asume de manera real su obligación en torno a la protección de la integridad y la dignidad del colectivo al que representa. La democracia representativa no imputa la responsabilidad a un solo gobernante, elegido por unos cuantos, sino que es el grupo mismo quien se hace intencionalmente responsable. En este sentido, hablar de una ciudadanía diferenciada conlleva pensar una democracia dentro de la cual los representantes no son elegidos por individuos -en un choque de intereses plurales-, sino que hacen parte del grupo, se reconocen como parte de este por sus diferencias, identifican las necesidades del colectivo y, a la hora de tomar decisiones, está en permanente conversación con él. En otras palabras, 
una ciudadanía diferenciada conlleva pensar en un autogobierno en el cual el Estado no prevalece ni se impone ante la autoridad de las comunidades o pueblos, sino que las acepta, siempre y cuando estas operen bajo los principios generales de igualdad y libertad. Son las comunidades quienes reivindican el autogobierno con plenos derechos de autonomía y autodeterminación (Tamayo, 2006, p. 22).

La ciudadanía diferenciada pretende, entonces, la justicia social de sus instituciones. Asimismo, es una apuesta por el trabajo conjunto de los colectivos particulares que componen el Estado. Una construcción en la que cada grupo social se responsabiliza del cuidado de sí, a través del autogobierno.

Precisamente, la virtud de la ciudadanía liberal es la justicia de sus instituciones, la identidad nacional, la tolerancia, y el trabajo y la relación armónica entre particulares. La participación en los procesos políticos a través de mecanismos procedimentales e institucionales garantizan el equilibrio entre poderes, y hace que los individuos acepten al interior de la comunidad política la responsabilidad personal de sus propios actos. (Tamayo, 2006, p. 22)

La ciudadanía diferenciada es una puerta de entrada para

[...] concebir la justicia social centrada en las posiciones que organizan la estructura social, es decir, en el conjunto de espacios sociales ocupados por los individuos, ya sean mujeres u hombres, miembros de minorías visibles o de la mayoría "blanca", "cultos" o menos "cultos", jóvenes o menos jóvenes, etc. (Dubet, 2012, p. 42)

Es una pretensión por una igualdad real de posiciones y estatus de dignidad, la cual pretende ajustar a los grupos diferenciales y su territorio las posiciones sociales sin poner el acento en la circulación de los representantes de las mayorías, sino en los diversos sujetos que se han reconocido como desiguales jurídica, social y moralmente.

\section{Hacia una democracia pluralista en Colombia}

La apuesta de una democracia pluralista, como forma de gobierno en Colombia, aduce al reconocimiento de las características de esta y su pertinencia frente a las necesidades de un pueblo que ha empezado a reaccionar ante los acontecimientos de los últimos 
años, los mismos que evidencian un efecto dominó del régimen autoritario, el cual se ha presentado bajo el disfraz de un gobierno democrático. Al igual que en México, en Colombia "la lucha entre conservadores y liberales se expresó de manera conflictiva y contradictoria, a veces impulsando alianzas, otras veces enfrentados en luchas fratricidas entre las principales fuerzas políticas del país" (Tamayo, 2006, p. 23). Fueron muchos años de violencia bipartidista. En respuesta a esto, han pululado una serie de partidos políticos con ideologías híbridas que median entre las posturas polarizadas, y otros más que se alejan, en su totalidad, de estas. No obstante, como lo refiere Bordeau (1982), "nuestras democracias quieren ser fieles a la herencia clásica; quieren salvar las conquistas liberales y, ante todo, la autonomía de la libertad" (p. 38). Por esto, quienes se mantienen en defensa de un gobierno autoritarista y centralizado conciben que las democracias pluralistas atentan contra la libertad, y no ven más allá, para reconocer en su esencia el ejercicio de un control libertario.

No se conciben otros significados para la democracia, más que el aceptado en la concepción clásica; con lo cual persiste el fundamento de una apuesta por la práctica tradicional, en la que se ejerce el poder absoluto centralizado en la figura de un representante que no da respuesta a las necesidades del colectivo y su contexto, además de imponer intereses y los de su partido político.

Es innegable que "a raíz de la creciente diferenciación funcional, la centralidad de la política como instancia máxima de representación y conducción de la sociedad se diluye" (Lechner, 1995, p. 11). Por esto, se debe pensar en un ejercicio político en el que en realidad el poder lo tenga la fuerza del pueblo. Para lo cual las democracias pluralistas se tornan como una alternativa viable, cercana y real, pues el pueblo ha optado por la pluralidad política, al crear nuevos partidos, entonces, ¿por qué no apostar por la pluralidad democrática?

Podría decirse que la conformación del colectivo de congresistas es una apuesta para la democracia pluralista, pues está estipulado, por decreto, que los representantes al Congreso y a la Cámara tengan un número de curules asignados para cada partido político y estas deben ser respetadas. Sin embargo, el poder centralizado y otorgado al jefe de Estado le concede una autoridad suprema para organizar su equipo de trabajo, el cual es seleccionado, no por las capacidades que deben tener los gobernantes - mucho menos por su prudencia y razonabilidad-, sino por intereses del movimiento político en el mando, con lo cual se construyen carruseles de corrupción en los que "el 
ganador se lleva todo en lo que toca a cargos públicos y recursos estatales" (Lanzaro, 2004, p. 103).

Por esto, las democracias pluralistas abren la bifurcación a una nueva forma de gobierno, en la que los intereses colectivos priman y se imponen en la realidad jurídica, económica y social. Así, esta concepción de democracia no solo favorecerá la política, sino todas las esferas del Estado y su funcionamiento, lo que, a su vez, se torna más real para establecer coherencia entre lo que postula la teoría y lo que se manifiesta en la práctica. Podría decirse que este es otro elemento que converge con el pensamiento de Spinoza, para quien - como lo expone Valero-Martínez (2018) — la democracia supone la acción conjunta de varias partes concebibles por separado y se evidencia tanto en la teoría como en la práctica política. De igual forma, apostar por un gobierno bajo el modelo de las democracias pluralistas permitirá frenar los procesos fraudulentos que se han presentado en las últimas elecciones.

Ahora bien, es innegable que la propuesta no es del gusto de quienes pertenecen a los partidos tradicionales del régimen autoritario, dado que "ello plantea al poder soberano la necesidad de renovarse para poder seguir desempeñando, bajo nuevas formas, funciones relevantes en la sociedad global” (Attili, 2007, p. 48). Además, de exigirle a los gobernantes el diálogo tolerante en la diversidad política, lo que implica ir en contra de "dogmas sediciosos o turbulentos que pueden representar inestabilidad o peligro para la colectividad" (Attili, 2007, p. 56); ya que, la fuerza del poder, como lo expone Bordeau (1982), la ejerce la organización social. En otras palabras, las democracias pluralistas implican poner una forma de gobierno en la que se reconozca el poder de las clases populares y se rompa con la soberanía de los representantes autoritarios que han acaparado por largos años el poder.

Es preciso anotar que, si bien en Colombia se ha ido abriendo el camino para el pluralismo político, los ciudadanos aún no están preparados para adoptar esta forma de gobierno, pues el ejercicio real y efectivo de la democracia plural incita, como lo expuso Young (1990), a la búsqueda de una ciudadanía diferenciada, en la cual las prácticas de los actores sociales en el contexto están determinadas por una cultura política que todos han creado y reconocen como útil a sus intereses. Una cultura política en la que hay compromiso de la colectividad para dar solución a sus propios problemas. Esto a su vez requiere iniciarnos en un proceso de formación ciudadana, en el que cada integrante se comprometa en su ejercicio, de tal forma 
que la legislación política y el derecho pasen a ser no un fin, sino un medio para regular la convivencia social.

En términos de Favela:

\begin{abstract}
Solamente en las sociedades democráticas pluralistas, hay ciudadanos que hacen de sus derechos una forma de convivencia social, constituyendo a través de esa convivencia una cultura política democrática en la cual, la dimensión jurídica es solamente un sustento institucional para que sea posible una práctica histórica y política que en cada país tiene derroteros diversos, ricos y variados que se construyen a partir de las necesidades, propuestas y acciones que los mismos ciudadanos van generando a cada momento de su devenir como sociedades. (Favela, 2007, p. 88)
\end{abstract}

Así, los ciudadanos son quienes se responsabilizan para crear y velar por el cumplimiento de las leyes. Regulan las prácticas de aquellos a quienes han elegido para representarlos en el poder, lo que descentraliza el ejercicio autoritarista. En palabras de Rodríguez (2019), ejercen una ciudadanía para el reconocimiento de su voz y voto como agentes políticos y, con esto, movilizan cambios sustanciales en los sistemas jurídicos para alcanzar un reconocimiento como sujetos de derechos y deberes.

Cabría preguntarse entonces: ¿cuáles son los elementos que deben primar en una formación ciudadana que favorezca el pluralismo político y que promueva una democracia pluralista? Como se ha expuesto al inicio, las grandes falencias que evidencian nuestro ejercicio ciudadano oscilan entre la pérdida de la memoria histórica, el bajo nivel de criticidad y el desconocimiento del papel que ejerce la ciudadanía al participar en la elección de sus representantes. Por esto, urge pensar en un tipo de formación ciudadana que promueva espacios de discusión en los que se fortalezcan las habilidades para el pensamiento crítico, como lo plantea Rodríguez (2018); en el que se argumente con conocimientos confiables sobre lo que convoca el pluralismo político y el ejercicio de la ciudadanía dentro de este y se reconozcan las necesidades contextuales y las diferencias políticas. Espacios de formación en los que se toleren los colectivos plurales y se asuman actitudes de prudencia al reconocerse cada sujeto como parte de una organización social que determina la fuerza del poder para orientar el rumbo político, económico e histórico de su sociedad. Espacios de discusión en los que cada ciudadano asuma un compromiso con el pacto social, mismo que se adquiere 
en el uso del lenguaje, a través de la creación de normas y declaraciones con las que protegerá sus derechos y los de los ciudadanos que se diferencian de la generalidad.

Así, la capacidad crítica se torna fundamental, no solo en la construcción del contrato social que regulará el comportamiento, sino a la hora de analizar los discursos de quienes intentan manipular al pueblo y abusar de su poder. Una formación para la ciudadanía crítica logrará que los grupos sociales se empoderen y demarquen los lineamientos políticos y jurídicos en defensa de sus derechos al controlar la fuerza del poder a través de los representantes elegidos colectivamente. En tal sentido, los ciudadanos analizarán las necesidades del contexto en aras de ofrecer la mejor solución a través de su ejercicio en las democracias pluralistas.

\section{Referencias}

Attili, A. (2007). Soberanía. En G. E. Emmerich y V. A. Olguín (coords.), Tratado de ciencia política (pp. 47-65). Barcelona: Antrophos editorial.

Aziz- Nassif, A. (1998). La ciencia política: empirismo, fortaleza vacía, hibridación y fragmentos. México: UnAM.

Bello, D. (2014). Democracia participativa y ciudadanía diferenciada para una convivencia intercultural de respeto a los derechos indígenas. En Democracia intercultural. México: Instituto Nacional Electoral (INE).

Brett, R. (2009). Etnicidad y ciudadanía. Guatemala: Programa de las Naciones Unidas para el Desarrollo.

Bordeau, G. (1982). Tratado de ciencia política. México: UnAM.

Canto, R. (2017). Participación ciudadana, pluralismo y democracia. Tla-Melaua: revista de ciencias sociales, 10(1), 54-75.

Castellanos, A. y Pérez, R. (1981). El pluralismo. Examen de la experiencia uruguaya (1830-1918). Montevideo: Claeh Montevideo.

Dubet, F. (2012). Los límites de la igualdad de oportunidades. Nueva Sociedad, 239, 42-50. 
Duque, Javier. (2012). La democracia en Colombia: entre los déficits y la insatisfacción de los ciudadanos. Perspectivas internacionales, 8(2), 20-39.

Favela, A. (2007). Ciudadanos y derechos humanos. En G. E. Emmerich y V. A. Olguín (coords.), Tratado de ciencia política (pp. 87-103). Barcelona: Antrophos editorial.

Gros, H. (2002). El constitucionalismo latinoamericano y la codificación en el siglo XIX. Anuario Iberoamericano de Justicia Constitucional, 6, 143-176.

Kymlicka, W. (1996a). Ciudadanía multicultural. Barcelona: Editorial Paidós Ibérica, S.A.

Kymlicka, W. (1996b). Nacionalismo Minoritario dentro de las democracias liberales. En G. Soledad y L. Steven (comps.), Ciudadanía justicia social, identidad y participación (pp. 217-234). Madrid: Editorial Siglo XXI.

Lanzaro, J. (coord.). (2000). La segunda transición en el Uruguay. Montevideo: Fundación de Cultura Universitaria.

Lanzaro, J. (2004). Fundamentos de la democracia pluralista y estructura política del Estado en Uruguay. Revista uruguaya de ciencia política, 14, 103-135.

Lechner, N. (1995). Cultura política y gobernabilidad democrática. México: IFE.

Levitsky, S. y Ziblatt, D. (2018). Cómo mueren las democracias. Barcelona: Ariel.

Leyva, X. (2005). Indigenismo, indianismo y “ciudadanía étnica”. De cara a las redes "neo-zapatistas". En P. Davalos (comp.), Pueblos indígenas, Estado y democracias (pp. 279-309). Buenos Aires: Clacso.

Platón. (1988). República. En E. Alegre Corrido (ed.), Obra completa II. Madrid: Editorial Gredos, S. A.

Rodríguez, A. M. (2018). Elementos ontológicos del pensamiento crítico. Teoría de la Educación, 30(1), 53-74. DoI: http://dx.doi.org/10.14201/teoredu3015374

Rodríguez, A. (2019). El concepto “minorías”. Significados y usos. Revista Derecho de las Minorías, 1, 1-16.

Rousseau, J. (1991). Discours l'origine... En Oeuvres complètes III. Paris: Ed. Gallimard. 
Rousseau, J. (2003). Del contrato social (Mauro Armiño, trad.). Madrid: Alianza.

Spinoza, Baruch. (1986). Tratado teológico-político. Madrid: Alianza.

Tamayo, S. (2006). Entre la ciudadanía diferenciada y la ciudadanía indígena ¿otra es posible? El Cotidiano, 21(137), 7-17.

Valero-Martínez, J. (2018). Sobre los dos conceptos de democracia en Spinoza. Madrid: Punto crítico. Recuperado de: https://puntocritico.com/ausajpuntocritico/2018/07/06/sobre-los-dos-conceptos-de-democracia-en-spinoza-por-joseangel-valero-martinez-parte-i/

Vergara, J. (2012). Democracia y participación en Jean-Jacques Rousseau. Revista de filosofía, 68, 29-62.

Villaverde, M. (2002). Spinoza, Rousseau: dos concepciones de democracia. Revista de Estudios Políticos, 116, 85-116.

Young, I. (1990). Justice and the Politics of Difference. Princeton: Princeton University Press. 